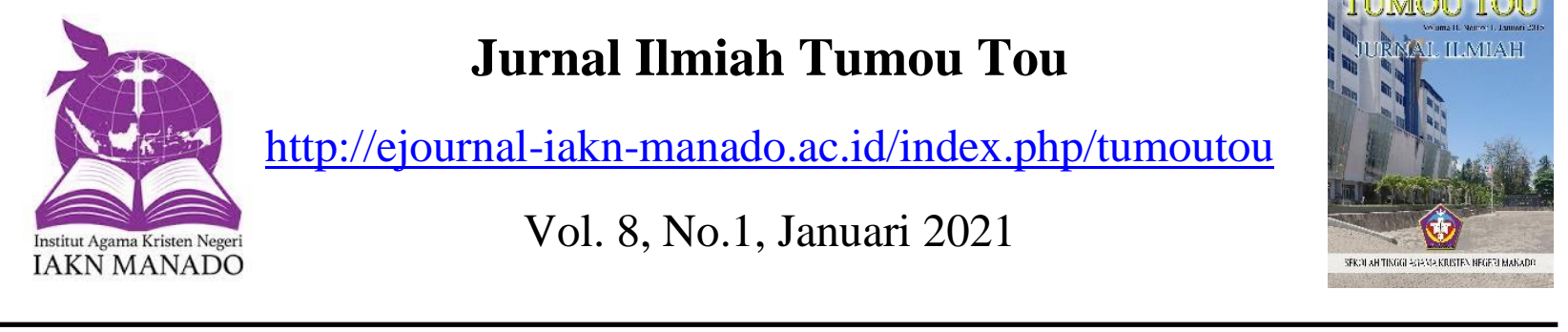

\title{
Religioteinment Sebagai Fenomena Globalisasi: Sebuah Perspektif Antropologi Agama
}

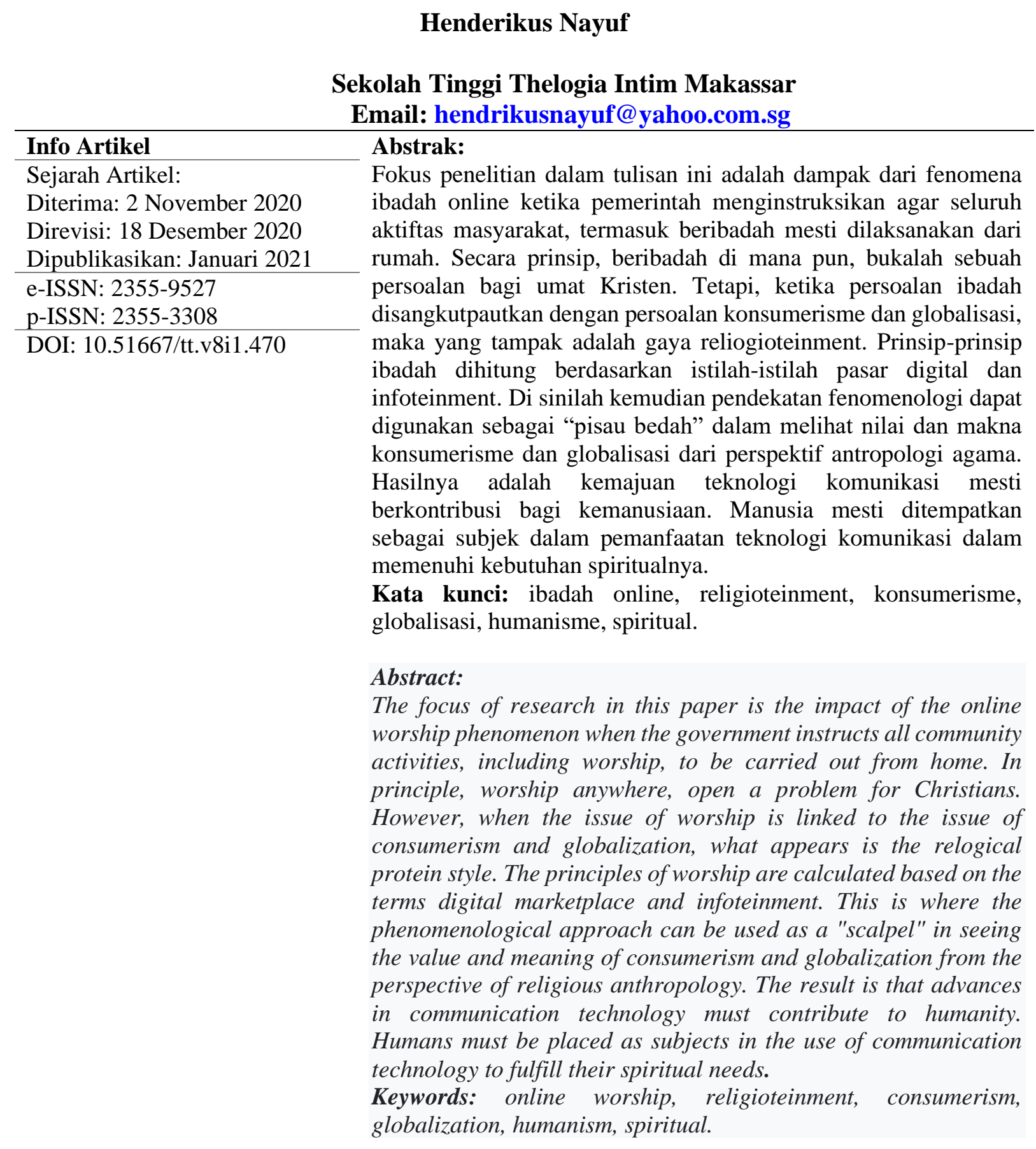




\section{PENDAHULUAN}

Istilah reiligioteinment adalah sebuah istilah yang dimunculkan oleh Stella Y. E. Pattipeilohy dan Yahya Wijaya dalam kajian mereka terhadap fashion sebagai isu budaya populer. Pattipeilohy dan Wijaya terinspirasi oleh penampilan Sr. Cristina, seorang rohaniawan Katolik diajang sebuah pencarian bakat, The Voice of Italy, pada tanggal 19 Maret 2014. The Guardian, situs internet yang dikutip Pattipeilohy dan Wijaya (2018), pada tanggal 21 Maret 2014 mewartakan berita tentang keikutsertaan Sr. Cristina dengan tema Singing nun Christina Scuccia becomes internet star after The Voice audition. Menurut the guardian, penampilan Sr. Christina dipandang mewakili suatu fungsi komunikatif. Busana, pakaian, kostum, salib, dan dandanan seorang religius perempuan dari Sr. Christina adalah bentuk komunikasi artifaktual (artifactual communication). Komunikasi artifaktual didefenisikan sebagai komunikasi yang berlangsung melalui pakaian dan penataan pelbagai artefak, misalnya pakaian, dandanan, barang perhiasan, kancing baju, atau furniture (Ibrahim, 2006). Dengan diskursus postmodern yang membedakan antara postmodernitas dan postmodernisme, Pattipeilohy dan Wijaya memberikan beberapa pendasaran teoritis untuk menunjukkan pengaruh globalisasi hingga ruang-ruang religius. Postmodernitas adalah praksis sosial yang menunjuk pada situasi dan tata sosial produk teknologi informasi, globalisasi, fragmentasi gaya hidup, konsumerisme, deregulasi pasar uang dan sarana public, usangnya Negara bangsa dan penggalian kembali inspirasi-inspirasi tradisi. Sementara itu, postmodernisme adalah dimensi teoritis tentan kritik-kritik filosofis atas world view, epistemology, dan ideologi-ideologi modern. Postmodernitas dilihat sebagai praksis sosial dan budaya dalam perubahan yang sedang terjadi, sementara postmodernisme adalah sebuah gerakan intelektual untuk menjelaskan perubahan sosial-budaya dalam arti luas yang sekarang sedang terjadi Pattipeilohy dan Wijaya (2018).

Dari catatan pendahuluan di atas, Pattipeilohy dan Wijaya kemudian merefleksikan "tindakan" Sr. Christina sebagai bagian dari wujud misi yang kontekstual. Bahkan, keikutsertaan Sr. Christina ditafsirkan sebagai bagian dari mengikuti anjuran "Bapa Suci - Paus" untuk pergi ke lorong-lorong kota dan mewartakan Injil. Walau demikian, dalam refleksi teologi moral, Pattipeilohy dan Wijaya (2018), menyampaikan bahwa ritual keagamaan mesti diberi muatan spiritualitas keutamaan pokok yakni keugaharian atau hidup sederhana. Di sinilah kemudian Pattipeilohy dan Wijaya mengatakan, "ritual keagamaan tidak perlu tergeser menjadi religioteinment, yang rela mengorbankan nilai-nilai moral dan spiritual demi daya tarik.

Persoalan yang kemudian menjadi inspirasi bagi saya untuk menulis artikel ini adalah munculnya fenomena ibadah online yang dilaksanakan oleh sebagian besar gereja-gereja di Indonesia sebagai respons atas anjuran pemerintah untuk beribadah dari rumah dalam rangka memutus rantai penyebaran Covid-19. Dalam wawancara dengan seorang pengurus gereja yang menangani multi media, saya menyimpulkan bahwa religiotenment telah menjadi bagian dari merebaknya ibadah online. Pengurus gereja itu mengatakan, tidak dipungkiri, bahwa jemaat yang mengikuti ibadah secara online melalui kanal youtube maupun live streaming, sering memilah-milah "actor" yang akan muncul dalam youtube maupun live streaming (Wawancara, 2020). Istilahistilah infotainment seperti: jam tayang, kejar tayang, rating tertinggi dan space market, tidak bisa dihindari dalam pelaksanaan ibadah online. Bagi penulis, ini adalah ciri-ciri religioteinment. Tulisan ini akan membahas ciri-ciri religioteinment dari perspektif postmodernisme. Dari pembahasan itu kemudian kita akan melihat 
kaitannya dengan globalisasi sebagai sebuah realitas dengan beragam fenomenanya. Pada bagian selanjutnya, kita akan melihat fenomena religioteinment sebagai bagian dari antropologi agama.

\section{METODOLOGI PENELITIAN}

Penelitian ini dilaksanakan dengan menggunakan pendekatan fenomenologi. Pendekatan ini dilandasi oleh refleksi atas perubahan besar dari antrophosentrisme kepada masa pencerahan. Perubahan besar itu pun berpengaruh pada paradigma dan metode. Salah satunya adalah munculnya pendekatan fenomenologis. Hardiansyah A (2013), mengatakan fenomenologi selain dapat dikatakan sebagai filsafat juga dikenal sebagai metode. Karena itu, Hardiansyah kemudian menegaskan bahwa objek pengetahuan adalah realitas sendiri yang menampakkan diri sendiri pada kita, melalui kesadaran yang intensional. Suatu fenomena tidak mesti diamati oleh indra yang lima buah itu, sebab fenomena dapat juga dilihat dan diamati secara rohan, tanpa melalui indra dan fenomena bukan suatu peristiwa. Realitas yang nampak tersebut kemudian dipahami dengan menggunakan intuisi. Pendekatan inilah yang menolong kita untuk memahami fenomena ibadah online di tengah situasi pandemi covid-19.

$$
\text { Pendekatan fenomenologi }
$$

menolong kita untuk memahami bahwa ilmu pengetahuan tentang penggambaran apa yang dilihat oleh seseorang atau yang dirasakan dan diketahuinya dalam immediate awareness and experience-nya. Penekanan pada proses penggambaran ini membawa kita kepada upaya mengungkapan kesadaran fenomenal atau kesadaran mengenai fenomena melalui ilmu pengetahuan dan filsafat menuju pengetahuan yang absolut (Ahimsa Putra, 2012).

\section{HASIL PENELITIAN DAN PEMBAHASAN}

Ciri-Ciri religioteinment: Sebuah
Pendekatan Postmodernitas
Sejauh yang saya ketahui, belum ada tulisan yang berbicara khusus tentang religioteinment. Walau demikian, dalam bagian ini, kita akan melihat ciri-ciri religioteinment dengan pendekatan postmodernisme. Dalam konteks itu, bagian ini akan mengikuti alur yang disampaikan oleh H. W. B. Sumakul (2012), bahwa postmodern menunjuk pada semua fenomena yang berkaitan dengan masa kini, di abad 21. Sumakul memberikan pembedaan antara postmodernisme yang menunjuk pada gerakan budaya, filosofis sedangkan postmodernitas menunjuk pada ruang geo politik. Post modernisme mencoba menjelaskan akar-akar filosofis di belakang pikiran-pikiran yang menganalisis realitas masyarakat kini. Sementara postmodernitas menjelaskan fenomena budaya, sosial, ekonomi dan mengidentifikasinya dalam masyarakaat kini. Pembedaan inilah yang kemudian, saya memilih untuk menggunakan pendekatan modernitas dalam rangka memahami ciri-ciri fenomena religioteinment.

Sumakul (2012), memberikan pendasaran historis terhadap modernitas dengan menempatkan zaman Renaisans dan pencerahan yang mempromosikan ekonomi progresif, rasionalitas administrasi dan diferensiasi Negara industrial kapitalis. modernitas mengacu pada kualitas hidup menjadi modern, menyimpulkan adanya perasaan pemutusan hubungan dengan tradisi kuno, serta kagum dan peka terhadap perubahan cepat yang menjadi hakikat dari eksistensi maryarakat modern. Diskursus tentang modernitas mengemukakan bahwa modernitas adalah "keserbaragaman transformasi ekonomik, politis, sosial dan budaya". Dengan demikian, modernitas juga berhubungan dengan perubahan budaya secara besarbesaran, kebingungan masyarakat karena berkurangnya peran tradisi kuno dan peradaban agraris. Postmodernitas adalah ruang geopolitics dari telekomunikasi. Dalam tataran praksis, Hendar Putranto (2005), mengatakan bahwa ide dasar dari 
gagasan modernitas ialah bahwa telah terjadi perubahan yang radikal dari ekonomi era industri yang berkutat seputar produksi barang dan jasa menuju ekonomi pasca industri yang diorganisasikan seputar konsumsi budaya, permainan media massa, dan perkembangan teknologi informasi.

Dengan memahami secara singkat konsep postmodernitas, maka kita akan melihat beberapa ciri postmodernitas yang akan menolong kita untuk tiba pada "celah" untuk menempatkan istilah religioteinment sebagai fenomena globalisasi. Celah tersebut dapat dilihat dari ciri-ciri sebagai berikut (Pattipeilohy dan Wahyu, 2018): pertama, postmodernitas menandai lahirnya suatu tatanan sosial baru, di mana kekuatan media dan budaya populer mengatur dan membentuk segala macam hubungan sosial. Budaya populer maupun citra media semakin banyak mendominasi rasa realitas dan mendefenisikan diri tersebut. Media khususnya, memainkan peran dalam mengonstruksi rasa ini akan realitas sosial maupun rasa tersebut sebagai bagian dari realitas. Kedua, dalam budaya postmodern, tampilan permukaan dan gaya menjadi lebih penting. Yang dipentingkan adalah mengonsumsi citra maupun tanda itu sendiri, bukan manfaatnya atau nilainilainya. Dalam budaya populer bahwa yang tampak mendominasi adalah apa yang dipermukaan dan gaya yang ditampilkan serta sifat main-main dan senda gurau dengan mengorbankan isi, substansi dan makna. Sedangkan sifat-sifat artistik, integritas, keseriusan, otentisitas, kedalaman intelektual dan narasi yang kuat cenderung diabaikan. Bahkan, gambaran dari realitas maya (virtual reality) dianggap riil ketimbang realitas itu sendiri. Ketiga, jika gaya mendahului isi, maka budaya massa pada akhirnya akan menundukan budaya tinggi (budaya seni, estetik dan refleksi). Keempat, gagasan-gagasan yang sebelumnya koheren dan tunggal mengenai ruang dan waktu mulai ditumbangkan, terdistorsi dan diragukan. Oleh karena itu, budaya populer postmodern tidak mementingkan rasa koheren ruang atau waktu. Hal ini merupakan hasil dari arus informasi tanpa batas dan realitas pun cepat berubah (realitas hiper) serta cepat berpindah, akibatnya ruang dan waktu semakin tidak koheren. Kelima, dunia postmodern metanarasi (meta-narrative) sedang ditumbangkan. Semua metanarasi termasuk agama, terbuka untuk dikritik dan menjadi kurang penting. Termasuk postmodernitas menolak klaim teori atau pengetahuan mutlak. Sifat budaya populer postmodern yang beragam, ikonoklastik, referensial, dan seperti kolase jelas mendapatkan inspirasi dari tumbangnya metanarasi.

Hal penting dari ciri-ciri di atas, menurut Pattipeilohy dan Wijaya (2018), adalah budaya populer postmodern membungkus berbagai perubahan radikal melalui peranan media sosial yang menghapuskan pembedaan antara citraan dan realitas di mana citraan dianggap lebih riil daripada realitas. Dari sinilah kemudian istilah reiligioteinment dikemukakan oleh Pattipeilohy dan Wijaya. Sebab, ruang ibadah yang sebelumnya menjadi sakral dan kudus, bersifat privasi kemudian terpublis secara luar melalui berbagai media sosial. Itu berarti religiositas umat beragama telah bergeser dari spiritualitas hirarkhis (transcendental - imanensi profane - kudus) menjadi spiritualitas virtual tanpa batas. Tayangan-tayangan yang diformulasi dengan menggunakan bahasa agama kemudian perlahan-lahan menyesuaikan diri dengan istilah-istilah teknis infotainment. Di dalamnya, kesiapan infrastruktur media, aktor yang ditampilkan dan juga konten atau isi dituntut mengikuti "selera pasar."

\section{Religioteinment sebagai Dampak Globalisasi}

Menurut Hendar Putranto (2005), diskusi pascamodernitas tidak bisa dilepaskan dari debat hangat seputar globalisasi. Suatu alasan yang diajukan di sini adalah mengingat kesamaan fokus perhatian dari literature tentang globalisasi maupun diskursus pascamodernitas, yaitu 
pada budaya (misalnya: media, konsumerisme, turisme). Salah satu ciri yang paling mengemuka dari globalisasi adalah dunia yang semakin terhubung satu sama lain, atau diistilahkan sebagai kesalingterhubungan (interconnectedness). Ciri ini yang dapat dijumpai dalam fenomena penamaan religioteinment. Ketika ibadah keagamaan di desain untuk mengikuti pola globalisasi, maka sebenarnya kita terlibat dalam proses kesalingterhubungan itu. Ketika televisi muncul sebagai sebuah "kotak ajaib" yang menghubungkan berbagai suku dari belahan dunia, Billy Graham, seorang televangelis, dengan yakin berkata: "I can preach to more people in one night on TV than perhaps Christ did in his entire time" (Saya bisa berkhotbah kepada lebih banyak orang dalam semalam di TV daripada yang mungkin telah dilakukan Kristus dalam seluruh hidup-Nya). Melihat fenomena ini, Idi Subandy Ibrahim (2011), mengatakan sebagai bentuk budaya dan dengan karakter budaya visualnya, kehadiran TV telah membawa konsekuensi-konsekuensi budaya yang mendalam. Kehadiran TV memberi perspektif baru dalam komunikasi massa. Komunikasi tidak lagi menjadi sebuah kebekuan dalam diskusi-diskusi monoton, tetapi mampu keluar dari ruang privasi (dalam pengertian bersifat kelompok kecil) kepada ruang publik. Ketika berada di ruang publik, komunikasi kemudian berhadapan dengan realitas dunia yang terus berubah dalam kemajuan teknologi komunikasi. Pada akhirnya, agama pun menjadi bagian yang harus berubah mengikuti pola komunikasi dunia (life style). Dalam konteks ini, kita perlu melihat beberapa catatan tentang dampak globalisasi terhadap reiligoteinment.

Ozgur Solakoglu (2016), dari

Turkish Military Academy / Turkey mengemukakan globalisasi merupakan sebuah integrasi dunia dalam wujud penyatuan ekonomi, capital, sosial budaya dan politik. Solakoglu memberikan beberapa contoh seperti IMF, Bank Dunia dan organisasi-organisasi bentukan global lainnya, misalnya: World Helath Organization (WHO), Perserikan BangaBangsa (PBB) dan lainnya. Dengan melihat fenomena tersebut, Solakoglu menyampaikan tiga perpspektif analisis yakni persepktif globalis, skeptik atau tradisionalis dan pasca skeptik atau transformasional. Ketiganya dijelaskan secara baik oleh Solakoglu demikian. Pertama, perspektif globalis. Menurut pendekatan globalis, peran Negara bangsa berkurang oleh keberadaan organisasi internasional seperti PBB dan dana Moneter International (IMF) atau oleh gerakan sosial. Tiga organisasi besar dunia yakni IMF, Bank Dunia, dan GATT telah menciptakan tatanan ekonomi baru dunia yang harus dipatuhi oleh Negara-negara bangsa (masyarakat dunia). Dengan demikian, ketiga organisasi tersebut mengurangi peran Negara bangsa serta gagasan Negara yang sejahtera. Hal yang sangat konkrit adalah melemahnya kebijakan pasar regional serta melemahnya tenaga kerja lokal. Dampaknya, Negaranegara menjadi lebih lemah. Menurut Oberoi, sebagaimana dikutip Solakoglu (2016), Negara kesejahteraan diubah menjadi Negara persaingan sebagai akibat dari integrasi system global. Karena itu, menurut perspektif ini, model yang tepat untuk bentuk Negara bangsa ini adalah model Negara persaingan, di mana Negara diubah dari pemerintahan nasional dan komprehensif menjadi bentuk "intervensi yang lemah" dan pemerintah yang rendah".

Salah satu globalis, yakni Ohmae membahas pentingnya Negara kawasan daripada Negara bangsa. Bagi Ohmae, kegiatan ekonomi, membantu membingkai masalah politik. Artinya, Negara bangsa tidak berhasil mengelola ekonomi. Negara bangsa dirancang untuk menghadapi "ketegangan etnis", "kebencian agama", dan "kebencian politik." Menurut Ohmae, Negara bangsa tidak rasional dan tidak terbuka untuk realitas global. Saskie Sassen mengusulkan bahwa komponen subnasional seperti Negara-negara regional atau kota-kota global akan memaksa 
Negara-negara nasional untuk mengambil bentuk Negara yang berbeda di masa depan. Artinya, pendekatan globalisasi dan neoliberal di seluruh dunia membutuhkan kebijakan yang berpusat pada pasar, bukan kebijakan yang berpusat pada Negara. Selain itu, Martin Wolf, dalam catatan Solakoglu (2016), mengatakan bahwa isolasi ekonomi suatu Negara menghasilkan hasil ekonomi yang mengecewakan seperti di Korea Utara dan Jerman Timur. Di era global, bagi Wolf, Negara-negara bangsa harus terbuka untuk bergabung dengan ekonomi dunia dan organisasi internasional jika mereka ingin menjadi Negara yang kuat. Singkatnya, perspektif globalis sangat tergantung pada pendekatan ekonomi.

Kedua, perpektif skeptik. Skeptik percaya bahwa globalisasi bukanlah proses baru, tetapi bentuk internasionalisasi yang berkelanjutan. Oleh karena itu, bagi skeptik, negara bangsa sedang tumbuh dan kita dapat melihat pertumbuhan itu terjadi di masa depan berdasarkan data historis saat ini dan berbagai bentuk yang terkait. Dalam hal ini, skeptik konsisten menghadirkan bukti empiris yang menunjukan bahwa peran Negara bangsa masih hidup dan perbatasannya efektif. Selain itu, peran Negara bangsa menjadi sangat sentral. Skeptik berpendapat bahwa organ-organ PBB adalah instrument bangsa-bangsa yang kuat untuk mencapai tujuan politik mereka. Skeptik percaya bahwa masa depan politik dunia terkait dengan negara-negara nasional dan implementasinya. Skeptik menolak gagasan tata kelola global. Mereka percaya bahwa apa yang terjadi atas nama globalisasi adalah internasionalisme, regionalisme dan kebijakan neo-liberal yang diciptakan oleh tatanan kapitalis.

Ketiga, perspektif post skeptik. Perspektif ini mengusulkan bahwa globalisasi adalah fenomena nyata dan mempengaruhi negara-negara. Dalam konteks ini, kekuatan eksternal seperti HAM, kebijakan kependudukan dan faktorfaktor seperti lingkungan hidup, pendidikan, tenaga kerja, dan imigrasi, semua memiliki peran besar untuk dimainkan dalam membentuk kembali struktur-struktur suatu bangsa. Hal menarik dari perspektif ini adalah tentang kedaulatan negara bangsa. Karena itu, Wade, salah satu sarjana pasca-skeptik menuduh bahwa globalisasi menciptakan tatanan baru, meningkatkan ketidaksetaraan antara negara. Salah satu contoh yang mengemuka adalah muncul AS sebagai salah satu pemain utama dalam globalisasi yang menegaskan perannya.

Ketiga catatan di atas menempatkan reliogioteinment sebagai sebuah realitas yang tidak mungkin dihindari. Sebagaimana disampaikan di atas, ketika Graham berkhotbah melalui TV dan menjangkau seluruh dunia maka agama sementara berada pada area religioteinment. Agama didesain untuk mengikuti space iklan produk yang hendak ditawarkan bersamaan dengan informasi tentang ajaran agama. Dalam hal ini, TV dipandang telah menjelma lebih dari sekedar produk teknologi, tetapi ia juga adalah suatu "bentuk budaya" (cultural form). Dalam pandangan Schultze, narasi televisi sekuler merupakan suara nubuat bagi kebudayaan yang lebih luas; mereka menafsirkan dunia di sekitar kita dan meritualisasikan pengalaman kita. Dalam menafsirkan dan meritualisasikannya, kita terus mengikuti desain pasar, agar tidak terus secara kualitatif. Sebagaimana saya singgung pada bagian pendahuluan, bahwa di kalangan masyarakat awam, gaya hidup yang ditampilkan oleh para tokoh agama maupun metode pewartaan berita pengajaran agama yang terus berubah menunjukkan bahwa agama telah mengikuti trend pasar globalisasi.

\section{Religioteinment Dan Sumbangannya Bagi Antropologi Agama}

Tidak mudah untuk "memaksa" fenomena religioteinment masuk dalam frame antropologi agama. Sebab, antropologi agama, sebagaimana subdisiplin antropologi lainnya memiliki 
metodenya yang khas. Sementara religioteinment masih berupa observasi yang kemudian disimpulkan sebagai sebuah gaya hidup. walau demikian, saya berusaha melihatnya dari pendekatan bahasa agama, sebagaimana disampaikan oleh Ade Solihat (2012), bahwa bahasa agama sebagai media komunikasi antar manusia dengan sesuatu yang supranatural (sesuatu yang bersifat gaib namun diyakini memiliki kekuatan memengaruhi alam semesta). Bahasa agama sebenarnya menggunakan symbol linguistic sebagaimana bahasa keseharian, namun bahasa agama dibedakan dari segi keunikan yang dirasakan atas interaksi tertentu, praktek tekstual atau situasi pembicaraan. Hal yang menonjol di sini adalah praktikpraktik penandaan. Bahasa agama, secara prinsip menyampaikan pesan dari yang tak terdefenisikan dalam tatanan sosial masyarakat.

Komarudin Hidayat, sebagaimana dikutip Solihat (2012), mendefnisikan bahasa agama dari dua perspektif. Yang pertama, adalah theo-oriented yakni memandang bahasa sebagai kalam ilahi yang kemudian diabadikan di dalam Kitab Suci. Yang kedua, antropho-oriented, yang memandang bahasa agama sebagai ungkapan serta perilaku manusia atau sekelompok manusia. Dua perspektif ini menjadi referensi untuk melihat di mana posisi religioteinment sebagai dampak dipraktikannya bahasa agama yang theooriented sekaligus ontropho-oriented. Artinya, gaya hidup yang kemudian merembes dalam agama memberi ruang bagi kita untuk berhati-hati dalam menggiring agama ke ranah publik yang tidak terkontrol. Dalam kondisi apa pun, bahasa agama mesti menjadi filter dalam membentengi agama dari serbuan globalisasi yang tanpa ampun memasuki semua dimensi kehidupan.

Solihat mengatakan bahasa agama memperlihatkan karakteristik unik yang membedakannya dengan bahasa keseharian. Jika bahasa keseharian memperhitungkan efektifitas dan ekonomi bahasa, maka bahasa agama justru memperlihatkan pengulanganpengulangan. Di sinilah kemudian, kita mesti hati-hati agar pengulanganpengulangan itu tidak dimaknai sebagai sesutu yang bersifat kuno, tetapi dilihat sebagai formulasi religious yang memiliki standar tertentu dalam membaharuinya. Yang menarik dari bahasa agama adalah disebutnya sebagai symbol pembeda. Bahasa agama memiliki kekhasannya tersendiri. Hal ini yang mestinya perlu dijadikan sebagai catatan kritis terhadap fenomena religioteinmet. Perubahan yang ditawarkan tetapi menjadi sebuah keniscayaan, tetapi perubahan itu tetap perlu memberi porsi khusus bagi symbol pembeda itu sendiri. pembeda itulah yang kemudian dijadikan sebagai ciri khas religiositas yang darinya dikembangkan antropologi agama.

Pada bagian akhir tulisan ini, saya menyampaikan dua keutamaan sebagai prinsip religiositas dari perspektif antropologi agama. Pertama, tentang ottentisitas. Kata "autentik" (dari bahasa Yunani "authentes" = penyebab / author) mau mengatakan bahwa seseorang membawa diri bukan sebagaimana ia diharapkan oleh lingkungan sosialnya, tidak begitu saja menyesuaikan diri dengan segala budaya, pola sikap, dan kelakuan yang diharapkan oleh masyarakatnya, melainkan menurut keasliannya, menurut bagaimana ia sebenarnya. Orang dinamakan autentik apabilan ia membawa diri sebagai dirinya sendiri, bukan sebagai orang jiplakan, orang tiruan, orang-orangan yang hanya membeo yang tidak mempunyai sikap pendirian sendiri karena ia dalam segala-galanya mengikuti mode, budaya citra, dan seterusnya. Dalam masyarakat konsumtif, bahwa jargonnya adalah "kamu bergaya maka kamu ada", maka yang terjadi adalah "komunikasi melalui penampakan luar menjadi dominan" (Chanye, 2002). Walau demikian, Magnis-Suseno optimis bahwa autentik itu dapat diwujudkan dan dipertahankan. Kita uatentik karena kita 
menghayati diri sendiri (cita-cita dan nilai yang dianut), apa yang dicintai, dihargai, dicita-citakan.

Dalam kaitan dengan ritual keagamaan catatan yang menarik adalah tidak perlu bergeser menjadi religiotanment, yang rela mengorbankan nilai-nilai moral dan spiritual demi daya tarik. Lawan dari menjadi menarik atau bergaya adalah Allah yang menjadi manusia yang tidak menarik. Itulah makna yang terkandung dalam teologi inkarnasi. Catatan ini menjadi sebuah kritikan dari perspektif teologi moral. Walau demikian, jika membaca apa yang disampaikan oleh Graham, catatan ini mesti dilihat sebagai sebuah sumbangan teologi moral, agar esensi dari teologi inkarnasi tetap terpelihara. Artinya, kita tidak menghindar dari realitas pandemic, karena itu, strategi kita pun mesti memperhatikan konteks saat ini.

Kedua, sophrosune adalah salah satu keutamaan pokok (cardinal vistues) sebagai kritik atas hidup bermewahmewahan dan buas dengan tuntutan mawas diri serta pengenalan diri. (Pattipeilohy dan Wijaya, 2018). Kata Yunani untuk sophorosune adalah artinya keugaharian, secara eksternal menggambarkan perilaku hidup lembut, tenang, sahaja, ugahari (artinya sedang, sederhana). Sophorosune yang berarti kesederhanaan, muncul sebagai hasil pengekangan, pengendalian dan pengaturan. Maka, kesahajaan merupakan karakter seseorang yang tahu batas, tahu menahan diri, tahu mengekang nafsu, sehingga memiliki ketahanan hati dan tidak jatuh dalam perilaku ekstrem atau berlebih-lebihan. Lebih dari itu, sophosorune, dalam pemaknaan Pattipeilohy dan Wijaya (2018), merupakan keutamaan serba pantas yang tampak dalam shame culture (budaya tahu malu).

Dalam konteks religioteinment, keugaharian menjadi relevan dijadikan gaya hidup. Keugaharian sekaligus menjadi nilai diri yang perlu diperjuangkan agar kita tidak terbawa arus atau terombang-ambing dalam pusaran budaya populer yang tidak selamanya positif. Perlu menahan diri dan mengekang nafsu dari gempuran artefakartefak budaya populer yang yan bisa saja mengaburkan makna dari ibadah online itu sendiri. Catatan reflektif dari Pattipeilohy dan Wijaya yang dapat saya jadikan sebagai sumbangan teologi moral adalah terkait dengan terbangunnya dialog dengan realitas hari ini. Paus Fransiskus mengingatkan warga dunia (minimal warga Katolik) agar "Janganlah segan-segan menjadi warga dunia digital. Sangatlah penting perhatian dan kehadiran Gereja dalam dunia komunikasi untuk berdialog dengan manusia masa kini untuk mengantar dia berjumpa dengan Kristus". Walau demikian, kita mesti bersifat kritis terhadap sikap konsumerisme. Hal ini penting, agar selalu ada sikap mawas diri dalam desain ibadah online sehingga aspek spiritualitasnya tidak tergeser oleh aspek hedonisme.

\section{KESIMPULAN}

Perubahan gaya hidup masyarakat tidak bisa dihindari. Begitu juga dalam bidang keagamaan kita. Nilai-nilai khas dari agama semakin kabur maknanya seiring kejerjalinan dunia yang selalu menghadirkan hal-hal yang baru dan bersifat hedonistik. Karena itu, perlu konstruksi yang mengedepankan nilai-nilai keagamaan, agar ibadah sebagai pusat kegiataan keagamaan tidak tergerus oleh spirit konsumerisme. Dalam kaitannya dengan globalisasi, nilai positif dari religioteinment adalah dua hal. Pertama, muncul kreatifitas yang mengikuti trend umat beragama. Kedua, dalam rangka itu, kekhasan dari agama mesti terus diperhatikan. Kita tidak mungkin menghindar dari realitas kemajuan yang begitu luar biasa. Tetapi, kemajuan itu mesti dijadikan sebagai kesempatan untuk menunjukkan identitas keberagamaan kta.

Nilai penting dari religioteinment dalam kontribusinya terhadap antopologi agama adalah perlu memberi perhatian serius pada nilai-nilai humanism. Artinya, kemajuan teknologi mesti memberi 
manfaat bagi manusia itu sendiri. manusia tidak boleh dijebak untuk masuk dalam kerangkeng keterasungan, meskipun menikmati berbagai fasilitas zaman yang mengglobal. Dari sinilah, kita kemudian menyadari bahwa kemajuan ilmu pengetahuan, teknologi komunikasi mesti berkontribusi bagi kemaslahatan umat manusia.

\section{DAFTAR PUSTAKA}

A., Hardiansyah. Teori Pengetahuan Edmund Husserl, dalam Jurnal SUBSTANTIA, Vol. 15, No. 2, Oktober 2013.

Ahimsa-Putra, Hedy Shri. Fenomenologi Agama: Pendekatan Fenomenologi untuk Memahami Agama, dalam Walisongo, Vol. 20, Nomor 2, November 2012.

Barnard, Malcolm. Fashion sebagai

Komunikasi, Cara Mengomunikasikan Identitas Sosial, Seksual, Kelas dan Gender. Yogyakarta : JALASUTRA, 1996.

Chaney, D., Lifestyles: Sebuah Pengantar

Komprehensif. Yogyakarta : JALASUTRA, 2002.

Ibrahim, Idi Subandy. Kritik Budaya

Komunikasi, Budaya, Media, dan Gaya Hidup dalam Proses Demokratisasi di Inonesia. Yogyakarta : JALASUTRA, 2011.

Magnis-Suseno, Franz. Otensitas dan

Perkembangan Budaya, dalam Majalah BASIS No. 50.

Pattypeilohy, Stella Y.E., Yahya Wijaya.

Kajian Teologi Moral terhadap Fashion sebagai Isu Budaya Populer, dalam Kawistara, Vol.8, No. 1, 22 April 2018.

Putranto, H. Analisis Budaya dari

Pascamodernisme dan

Pascamodernitas, dalam Mudji

Sutrisno dan Hendar Putranto (ed.)

Teori-Teori Kebudayaan.

Yogyakarta : Kanisius, 2005.

Shields, R. Virtual, Sebuah Pengantar

Komprehensif. Yogyakarta :
JALASUTRA, 2011.

Solakoglu, Ozgur. Three Different

Perspectives On The Role of The Nation-State In Today's Globalized World, dalam European Scientific Journal, September 2016/SPECIAL/Edition.

Solihat, Ade. Memahami Bahasa dalam

Perspektif Antropologi, dalam

Tony Rudyansjah (Peny.)

Antropologi Agama, Wacana-

Wacana Mutakhir dalam Kajian Religi dan Budaya. Jakarta : Penerbit Universitas Indonesia, 2012.

Strinati, Dominic. An Introduction of

Popular Culture. London : Routledge, 2004.

Sumakul, H.W.B. Postmodernitas, Memaknai Masyarakat Plural Abad 21. Jakarta : Libri, 2012. 